\title{
Laparoscopic versus open liver resections of posterolateral liver segments - a systematic review and meta-analysis
}

\author{
Mateusz Rubinkiewicz ${ }^{1}$, Magdalena Mizera ${ }^{1}$, Piotr Małczak ${ }^{1}$, Natalia Gajewska ${ }^{1}$, Grzegorz Torbicz ${ }^{1}$, Michael Su ${ }^{2}$, \\ Konrad Karcz ${ }^{3}$, Michał Pędziwiatr ${ }^{1}$ \\ ${ }^{1} 2^{\text {nd }}$ Department of General Surgery, Jagiellonian University Medical College, Krakow, Poland \\ ${ }^{2}$ Faculty of Medicine, Jagiellonian University, Krakow, Poland \\ ${ }^{3}$ Clinic of General, Visceral and Transplantation Surgery, Ludwig Maximilian University, Munich, Germany
}

Videosurgery Miniinv 2020; 15 (3): 395-402

DOI: https://doi.org/10.5114/wiitm.2020.94268

\begin{abstract}
Introduction: Laparoscopic resection has become an accepted approach to liver tumour surgery. However, it is considered difficult, especially in unfavourably located lesions.

Aim: To compare the outcomes of laparoscopic (LLR) and open liver resection $(O L R)$ of posterolateral segments.

Material and methods: We searched the PubMed, EMBASE, and Scopus databases from inception to 30 September 2019. Full text articles and conference abstracts were included for further analysis. This review follows the PRISMA guidelines.

Results: From 643 articles, 15 studies ( $N=1196$ patients) were included in the meta-analysis. All of them were non-randomised. Our findings showed that LLR had significantly lowered overall morbidity compared to OLR (MD = 0.66; 95\% Cl: 0.51-0.86; $p=0.002)$. Length of hospital stay ( $M D=2.48 ; 95 \% \mathrm{Cl}:-3.87,-1.08 ; p<0.001)$ was also shorter in the LLR group. Operative time $(M D=55.65 ; 95 \% \mathrm{Cl}: 24.14-87.16 ; p<0.001)$ was significantly shorter in the OLR group. In terms of blood loss, major complications, $R O$ resection rates, and resection margin, there were no significant differences.

Conclusions: Our meta-analysis showed that the laparoscopic approach to resections of posterolateral liver segments is beneficial. However, the results are based on non-randomised trials, and further research is needed to fully establish their clinical application.
\end{abstract}

Key words: liver neoplasms, hepatectomy, laparoscopy, meta-analysis, systematic review.

\section{Introduction}

Laparoscopy has become the gold standard in many surgical interventions. Its advantages over an open approach are undisputable regarding postoperative pain, recovery time, and length of stay. Moreover, many authors underline that this approach is not inferior considering oncological outcomes [1-3].

However, liver surgery is considered a complex procedure with many technical difficulties. A signif- icant number of procedures are performed on cirrhotic livers with portal hypertension, making the surgery even more demanding [4]. The cirrhotic liver has limited abilities for regeneration, which forces surgeons to limit the extent of resected tissue to preserve liver function [5].

Despite the technical requirements, the laparoscopic approach proved to be a feasible method even for complex liver resections, surpassing an open approach in terms of reduced overall morbidity [6]. As 
an example, laparoscopic left sectionectomy has become a routine method; however, it is recommended only for experienced surgeons [7]. Nonetheless, little is known about the most difficult procedures, such as surgical removal of lesions localised in segments $4 \mathrm{~A}, 6,7$, and 8 (according to Couinaud classification), also known as posterolateral.

\section{Aim}

The aim of our study was to evaluate different aspects of laparoscopic liver resections of the posterolateral segments with regard to the safety (morbidity) and difficulty (operative time, blood loss).

\section{Material and methods}

\section{Search strategy}

In September 2019 a search of the Medline, Embase, and Scopus databases was conducted for publications on posterolateral resections of the liver. In an effort to be more comprehensive, we did not introduce any language restrictions to the search. Supplementary file 1 includes the full search strategy for the OVID platform. Also, we manually looked for other relevant publications in the referred studies.

Inclusion criteria for further analysis were: (1) studies comparing open and laparoscopic resections of the lesions located in posterolateral (4A, 6, 7,8 ) segments of the liver, and (2) reporting overall morbidity, operative time, and major complications.

Two independent teams performed abstract and full-text screening of the articles. Where inclusion of the study was debatable, the teams attempted to reach a consensus. In cases of doubt, the decision was made by a third, independent reviewer. The extraction of data was performed independently by both teams. In our study, we did not intend to re-

Initial search: 643 records

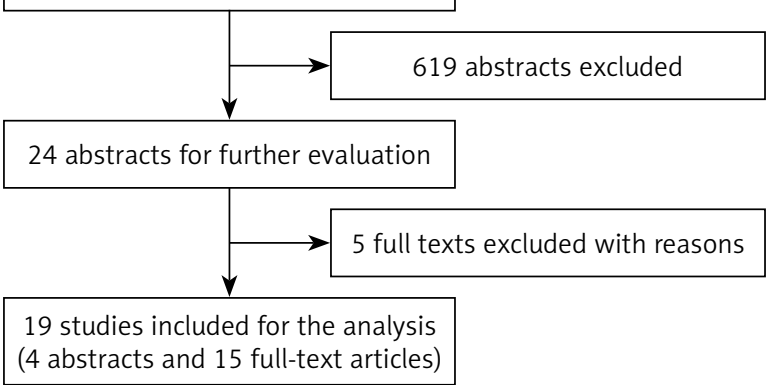

Figure 1. PRISMA flowchart trieve additional data that was not included in the manuscript directly from the authors. The study quality was assessed using the Newcastle-Ottawa scale [8].

\section{Outcome measures}

The outcome measures of this systematic review were: overall morbidity, major complications, operative time, intraoperative blood loss, resection margin, non-RO resection rate, and length of hospital stay.

\section{Statistical analysis}

For analytic purposes, we used RevMan 5.3 (freeware from the Cochrane Collaboration). Statistical heterogeneity and inconsistency were measured using Cochran's $Q$ tests and $1^{2}$, respectively. Qualitative outcomes from individual studies were analysed to assess individual and pooled risk ratios (RR) with pertinent $95 \%$ confidence intervals $(\mathrm{Cl})$, favouring laparoscopic over the open approach, and by means of the Mantel-Haenszel random-effects method. In cases when data were presented by medians and interquartile ranges, we calculated the mean \pm SD using a method proposed by Hozo et al. [9]. Weighted mean differences (WMD) with $95 \% \mathrm{Cl}$ are presented for quantitative variables using the inverse variance random-effects method. Statistical significance was observed at a two-tailed 0.05 level for the hypothesis and 0.10 for heterogeneity testing, while unadjusted $p$-values were reported accordingly. This study was performed according to the Preferred Reporting Items for Systematic Reviews and Meta-Analyses (PRISMA) guidelines and Meta-Analysis of Observational Studies in Epidemiology (MOOSE) consensus statement $[10,11]$.

\section{Results}

The initial search yielded 643 records after removal of the duplicates. After abstract screening we selected 19 studies, with 15 full texts available, covering 532 patients in the laparoscopic group and 664 patients in the open (1196 patients in total). The PRISMA flowchart presented in Figure 1 summarises the screening process. Baseline information on included studies is presented in Table I [12-26]. All studies eligible for evaluation with the Newcastle-Ottawa scale were ranked as high quality.

Overall morbidity was reported by 11 authors ( $N=1029$ patients). There was a significant differ- 
Table I. Details of included studies ordered by year ascending

\begin{tabular}{|c|c|c|c|c|c|c|c|c|}
\hline Study & Year & Design & $\begin{array}{l}\text { N Lap./ } \\
\text { Open }\end{array}$ & $\begin{array}{c}\% \text { male } \\
\text { Lap./Open }\end{array}$ & $\begin{array}{c}\text { Age } \\
\text { Lap./Open }\end{array}$ & Lesion type & $\begin{array}{l}\text { Full- } \\
\text { text }\end{array}$ & NOS \\
\hline Patriti [12] & 2014 & C & $19 / 63$ & $63.2 / 60.9$ & $62.6 / 63.2$ & $\begin{array}{c}\text { Metastasis, HCC, } \\
\text { Other }\end{array}$ & Yes & 7 \\
\hline Manoharan [13] & 2014 & C & $22 / 28$ & N/A & N/A & N/A & No & $\mathrm{N} / \mathrm{A}$ \\
\hline Cho [14] & 2015 & C & 24/19 & $70.83 / 84.21$ & $53.9 / 60.0$ & $\mathrm{HCC}$ & Yes & 8 \\
\hline Xiao [15] & 2015 & C & $41 / 86$ & $82.93 / 89.53$ & $52.1 / 50.3$ & $\mathrm{HCC}$ & Yes & 8 \\
\hline Guro [16] & 2017 & C & $58 / 61$ & N/A & $\mathrm{N} / \mathrm{A}$ & $\mathrm{HCC}$ & No & $N / A$ \\
\hline Scuderi [17] & 2017 & CM & $86 / 86$ & $62.8 / 58.1$ & 64.0/63.9 (median) & Metastasis, HCC & Yes & 7 \\
\hline Mariani [18] & 2017 & C & $30 / 51$ & $\mathrm{~N} / \mathrm{A}$ & $\mathrm{N} / \mathrm{A}$ & $\mathrm{HCC}$ & No & $\mathrm{N} / \mathrm{A}$ \\
\hline Araki [19] & 2017 & C & $10 / 11$ & N/A & N/A & & No & $N / A$ \\
\hline Li [20] & 2018 & C & $52 / 29$ & $32.7 / 31.0$ & 48.96 & $\begin{array}{c}\text { HCC, Hemangioma, } \\
\text { Metastasis }\end{array}$ & Yes & 8 \\
\hline Rhu [21] & 2018 & C & $53 / 97$ & $81.1 / 83.5$ & $58.0 / 58.2$ & $\mathrm{HCC}$ & Yes & 7 \\
\hline D’Hondt [22] & 2018 & CM & $35 / 35$ & $51.4 / 65.7$ & 64.0/64.0 (median) & $\begin{array}{c}\text { Metastasis, HCC, } \\
\text { Others }\end{array}$ & Yes & 7 \\
\hline Morikawa [23] & 2014 & CM & $20 / 20$ & $70 / 70$ & 64/65.5 (median) & $\begin{array}{c}\text { Metastasis, HCC, } \\
\text { Others }\end{array}$ & Yes & 9 \\
\hline Okuno [24] & 2018 & CM & $29 / 29$ & $48,3 / 51,7$ & 54/54 (median) & Metastasis & Yes & 9 \\
\hline Nota [25] & 2018 & CM & $31 / 31$ & $65 / 55$ & 59/57 (median) & $\begin{array}{c}\text { Metastasis, HCC, } \\
\text { Others }\end{array}$ & Yes & 8 \\
\hline Aghayan [26] & 2019 & C & $62 / 74$ & $50 / 65$ & $66 / 67$ & $\begin{array}{c}\text { Metastasis, HCC, } \\
\text { Others }\end{array}$ & Yes & 7 \\
\hline
\end{tabular}

C - cohort study, CM - case matched study, NOS - Newcasle-Ottawa Scale, HCC - hepatocellular carcinoma.

ence in favour of the laparoscopic approach: $M D=$ 0.66; 95\% Cl: 0.51-0.86; $p=0.002$ (Figure 2). The heterogeneity between studies was low; $I^{2}=0.02 \%$.

Major complications were reported in 10 studies ( $N=900$ patients). There were no significant dif- ferences between the groups: $M D=0.60 ; 95 \% \mathrm{Cl}$ : $0.35-1.00 ; p=0.05$ (Figure 3), and the heterogeneity between studies was low; $l^{2}=0 \%$.

Operative time was reported by 15 authors ( $N=1196$ patients). There were significant differ-

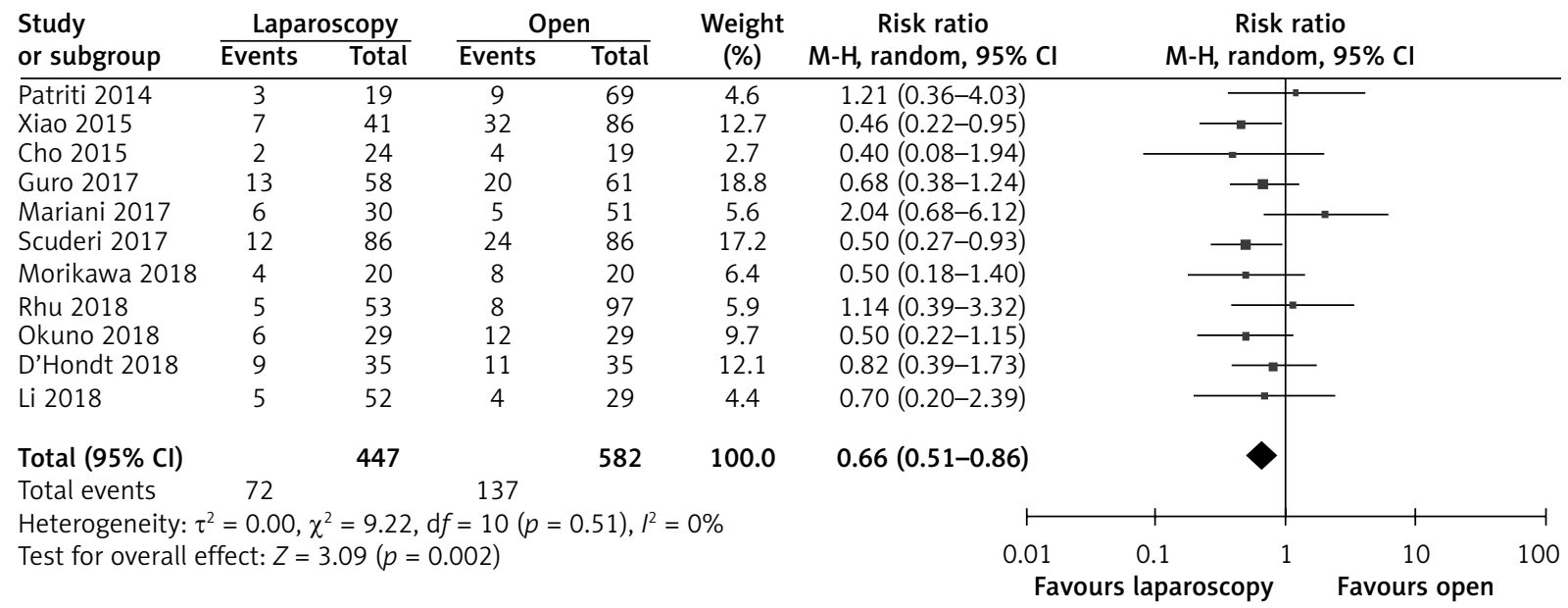

Figure 2. Overall morbidity

$\mathrm{Cl}$ - confidence interval, $\mathrm{df}$ - degrees of freedom, $\mathrm{M}-\mathrm{H}$-Mantel-Haenszel. 
ences in favour of the open approach: $M D=55.65$ $95 \% \mathrm{Cl}: 24.14-87.16 ; p<0.001$ (Figure 4), although the heterogeneity between studies was significant; $I^{2}=86 \%$.

Blood loss was reported by 12 authors $(N=862$ patients); however, two of them did not include all required data for further estimation $(S D, I Q R$, or range). There were no significant differences between the groups: $M D=-41.46 ; 95 \% \mathrm{Cl}:-220.02$, 260.00; $p=0.65$ (Figure 5). Heterogeneity analysis reported a substantial measure of $I^{2}=96 \%$.

Resection margin was reported by five authors ( $N=554$ patients). There were no significant differences between the groups: $M D=-0.23 ; 95 \% \mathrm{Cl}$ :
$-0.76,0.31 ; p=0.41$ (Figure 6). Heterogeneity between studies was again significant, with $l^{2}=72 \%$.

Non-R0 resection was reported by nine authors $(N=$ 903 patients), although the study by Rhu et al. did not have cases of non-RO resection in their material. There were no significant differences between the groups: $\mathrm{MD}=-0.89 ; 95 \% \mathrm{Cl}: 0.61-1.30 ; p=0.55$ (Figure 7). The heterogeneity between studies was low; $1^{2}=0 \%$.

Length of stay was reported by nine authors, including $N=803$ patients. There was a significant difference in favour of the laparoscopic approach: $\mathrm{MD}=-2.48 ; 95 \% \mathrm{Cl}:-3.87,-1.08 ; p<0.001$ (Figure 8$)$. However, heterogeneity between studies was significant, $l^{2}=87 \%$.

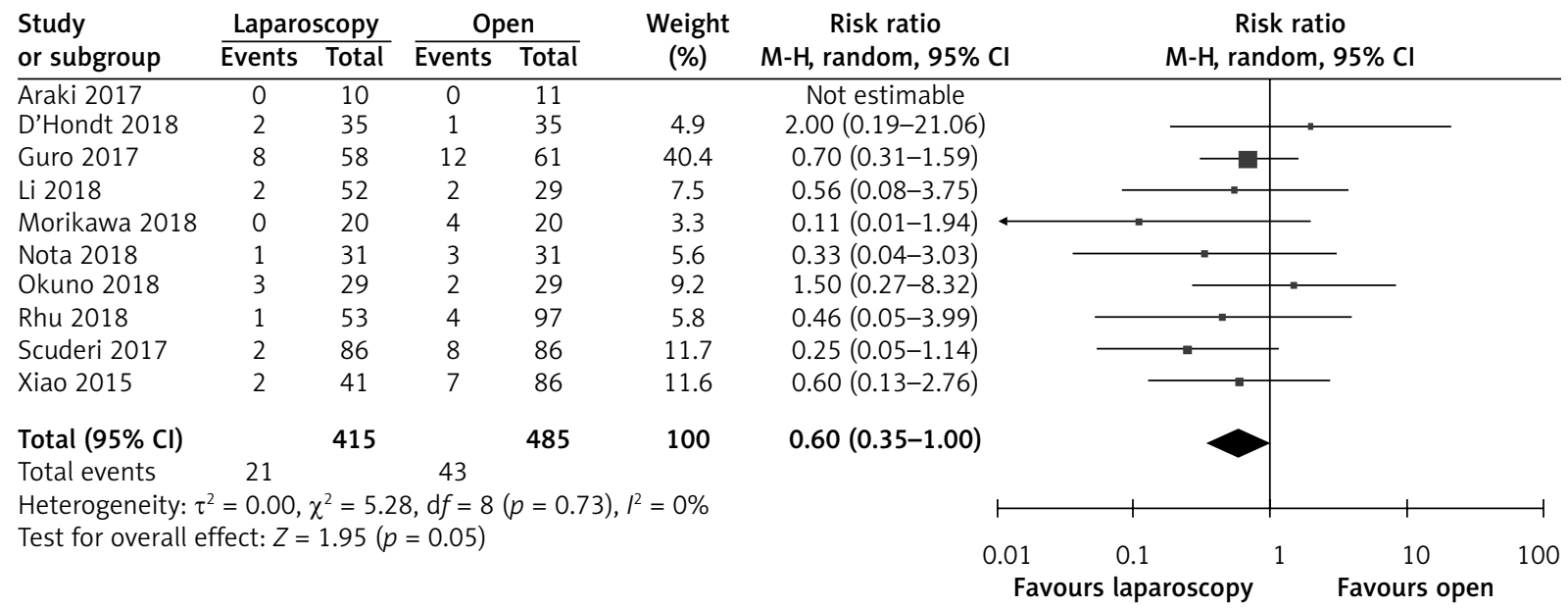

Figure 3. Major complications

$\mathrm{Cl}$-confidence interval, $\mathrm{df}$-degrees of freedom, $\mathrm{M}-\mathrm{H}$-Mantel-Haenszel.

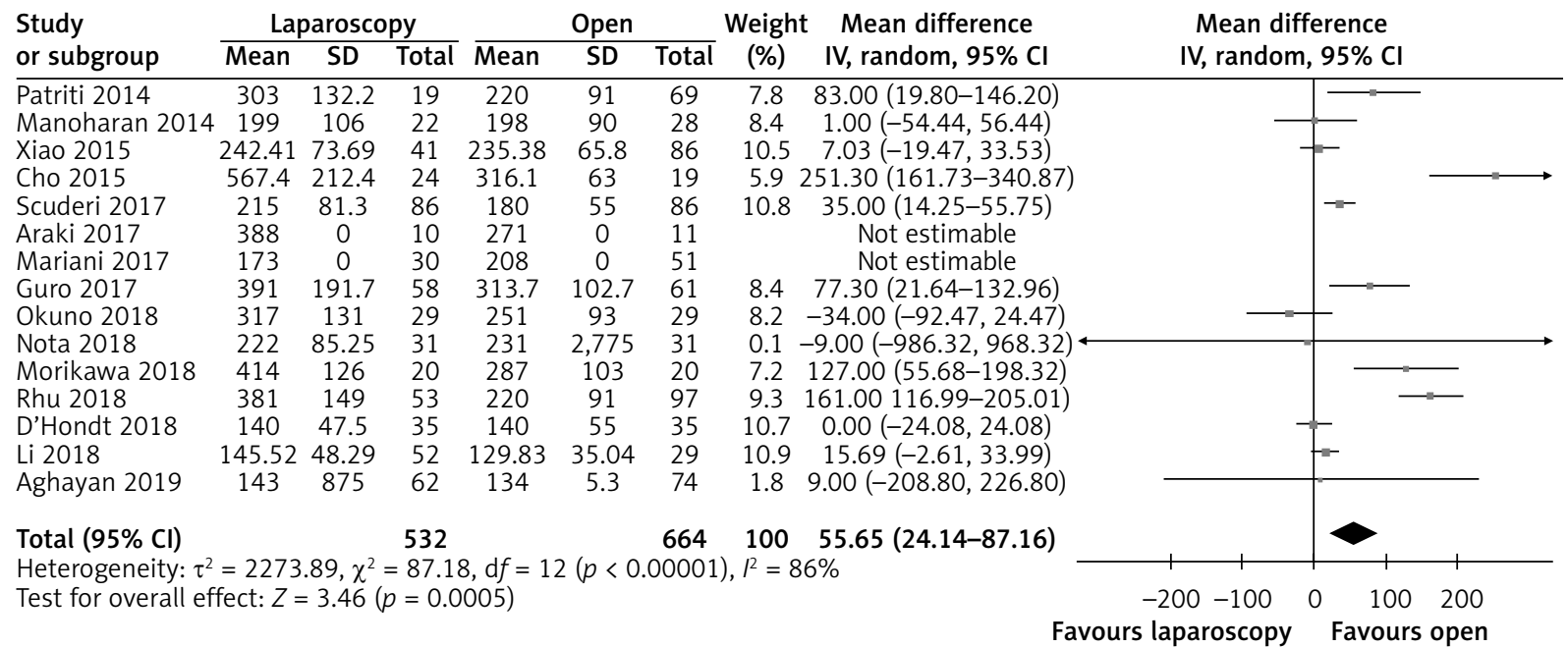

Figure 4. Operative time

$\mathrm{Cl}$-confidence interval, $d f$-degrees of freedom, IV - inverse variance. 


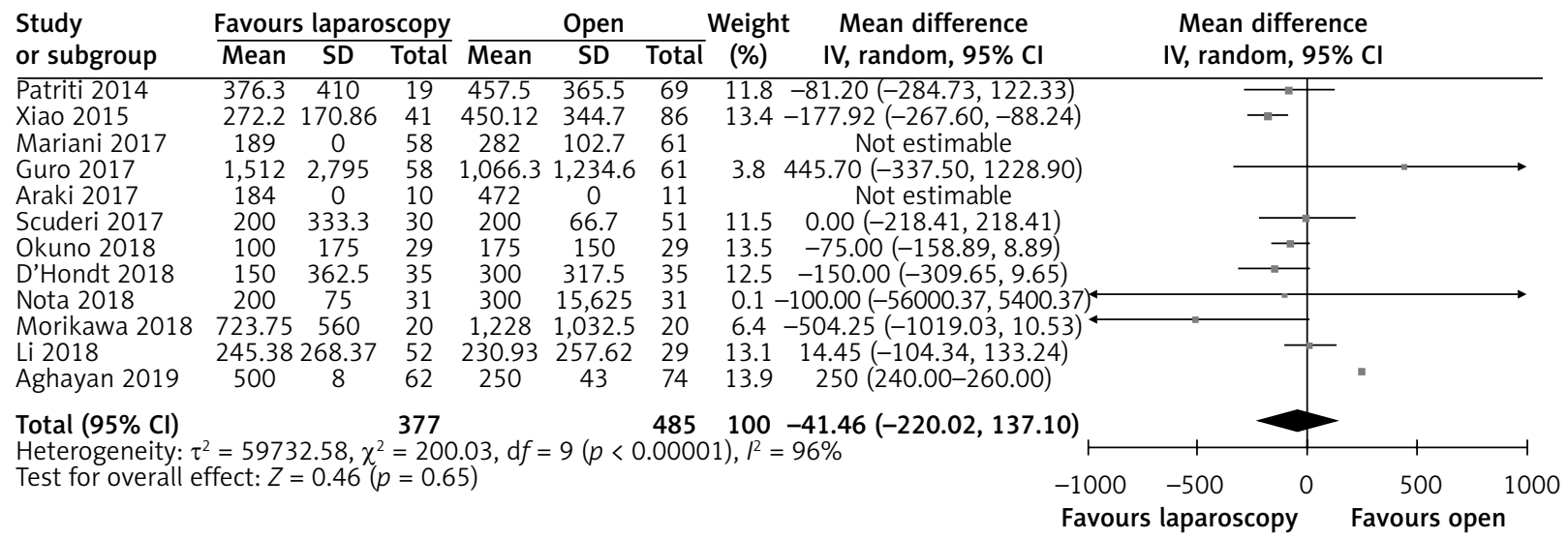

Figure 5. Intraoperative blood loss

$\mathrm{Cl}$-confidence interval, $d f$-degrees of freedom, IV-inverse variance.

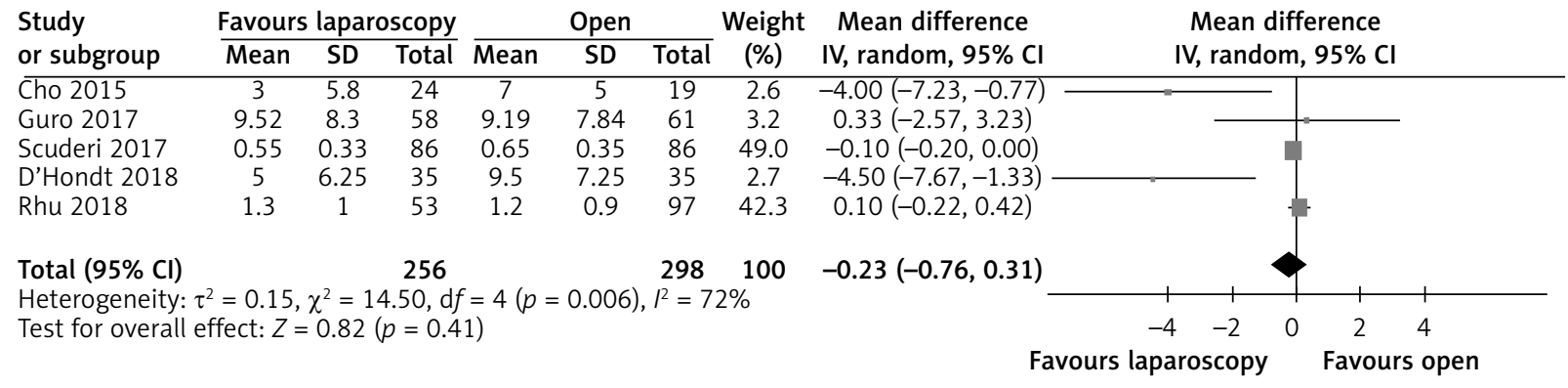

Figure 6. Resection margin

$\mathrm{Cl}$-confidence interval, $d f$-degrees of freedom, IV-inverse variance.

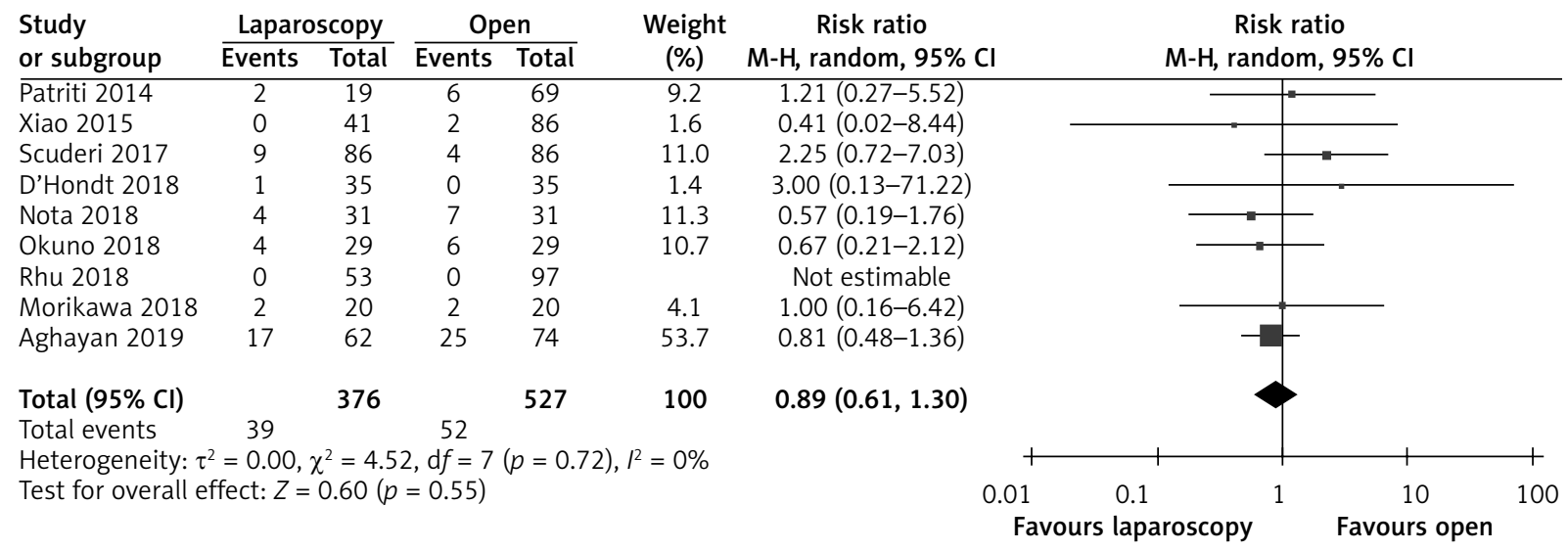

Figure 7. Non-RO resections

$\mathrm{Cl}$ - confidence interval, $\mathrm{df}$-degrees of freedom, $\mathrm{M}-\mathrm{H}$-Mantel-Haenszel.

\section{Discussion}

In our meta-analysis we revealed that posterolateral liver resection is both a feasible and safe method in the treatment of lesions localised in segments 4A, 6, 7, and 8. We showed that the laparoscopic approach is superior in terms of overall morbidity and length of hospital stay. An open approach had a shorter mean operative time. Due to the small number of studies comparing open and laparoscopic techniques in posterolateral resections, we decided to also include conference abstracts in order to obtain as much data as possible. It enabled us to analyse a group of 1196 patients. 


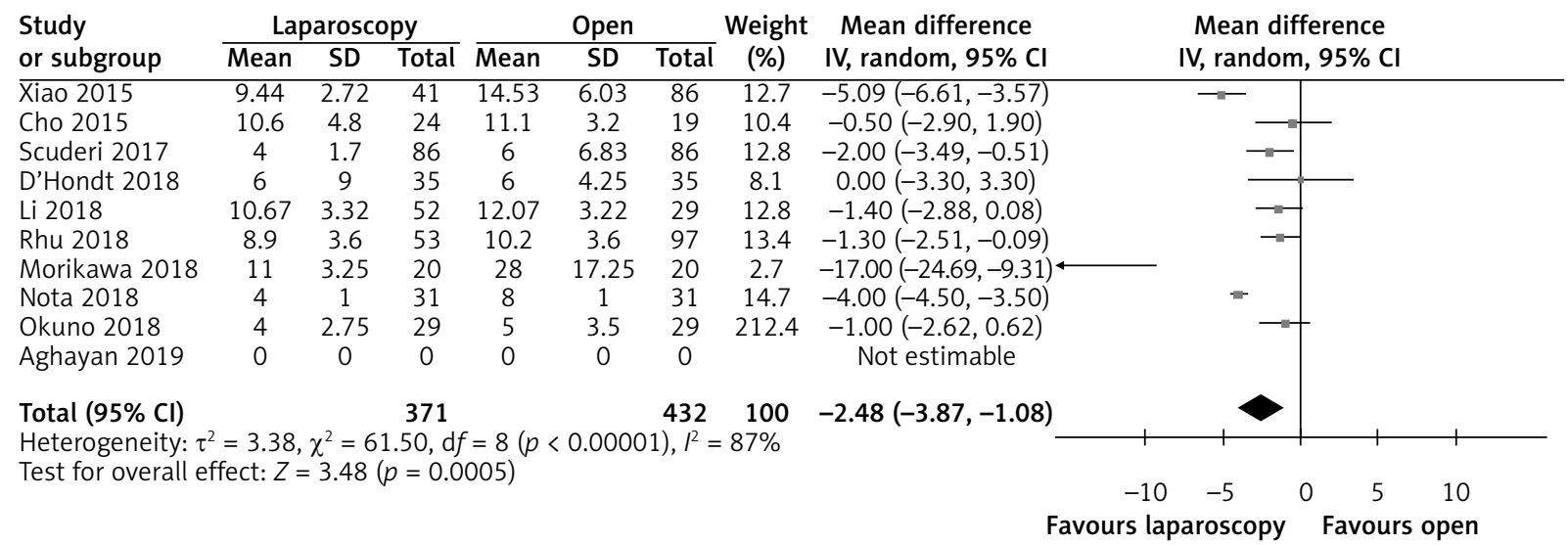

Figure 8. Length of hospital stay

$\mathrm{Cl}$ - confidence interval, $\mathrm{df}$-degrees of freedom, IV-inverse variance.

For the patients, one of the most important things during treatment is the safety of the procedure. In our study, we showed a number of benefits of laparoscopic technique in comparison to the open approach. At first, overall morbidity was lower in the laparoscopic group, and only three of the included studies reported lower morbidity in the open group $[12,16,18]$. Regarding major complications, the results were not statistically significant, although only D'Hondt et al. and Okuno et al. reported a higher rate in the laparoscopic group [22]. Nonetheless, meta-analyses considering all kinds of liver resections proved the laparoscopic approach to be both safe and efficient. Witowski et al. included 43 studies with 5100 patients treated for hepatocellular carcinoma [6]. In their study, not only morbidity was reduced in the laparoscopic group, but the perioperative mortality was also comparable.

Our analysis showed operative time to be shorter in the open approach. In general, major procedures with laparoscopic approach take longer than open surgery. However, in this specific case the learning curve might have affected the results. Longer surgery duration was found to be related to early phases of introduction of the laparoscopic approach [27]. It is very rarely reported whether surgeons have already reached the proficiency, which limits the possibility to interpret the results. Additionally, heterogeneity between the studies was high, making it difficult to generalise the clinical value. Moreover, longer surgery duration may have little impact clinical outcomes.

There is no consensus as to whether the laparoscopic technique decreases blood loss or not. Com- plex laparoscopic procedures have a steep learning curve, causing worse short-term outcomes at the beginning $[28,29]$. In our study, there were no differences between the groups. The only included research reporting higher blood loss was a study by Guro et al., although the results are not significant. We also did not analyse the rate of Pringle manoeuvres performed during the surgery, which diminishes blood loss in complex liver resections.

Length of stay was shorter in the laparoscopic group. It has previously been proven that the laparoscopic approach is beneficial for patients in terms of less postoperative pain and faster recovery and lower morbidity, which also leads to a faster discharge from the hospital [30]. Nonetheless, the heterogeneity between the studies was high, thus the results should be carefully interpreted.

Our study has some limitations. First, the procedures had been performed in high-volume centres, which limits the introduction of our conclusions to clinical practice in smaller hospitals. Second, there is no technical standardisation of the minimally invasive approach, which comprises different methods of dissection and trocar placement. Moreover, pooled analyses revealed significant heterogeneity in a number of evaluated outcomes. To minimise the negative impact of heterogeneity we used a random-effects model instead of a fixed one. We also performed sensitivity analyses without outlying studies. Furthermore, minimally invasive liver resections are complex and demanding procedures, requiring a suitable learning curve to gain proficiency. Most of the included studies commented on midsized groups of patients, which could diminish the 
positive effect of laparoscopic surgery. Finally, all analysed studies were non-randomised, which creates further bias and limits interpretability of the results.

\section{Conclusions}

Our meta-analysis showed that laparoscopic liver resections of posterolateral segments are beneficial. However, the results are based on non-randomised trials, and further research is needed to fully establish their clinical application.

\section{Conflict of interest}

The authors declare no conflict of interest.

\section{References}

1. Małczak P, Mizera M, Torbicz G, et al. Is the laparoscopic approach for rectal cancer superior to open surgery? A systematic review and meta-analysis on short-term surgical outcomes. Videosurgery Miniinv 2018; 13: 129-40.

2. Pędziwiatr M, Małczak P, Mizera M, et al. Pancreatoduodenectomy for pancreatic head tumors in the elderly - systematic review and meta-analysis. Surg Oncol 2018; 27: 346-64.

3. Bonjer HJ, Deijen CL, Abis GA, et al. A randomized trial of laparoscopic versus open surgery for rectal cancer. N Engl I Med 2015; 372: 1324-32.

4. Hackl C, Schlitt HJ, Renner P, Lang SA. Liver surgery in cirrhosis and portal hypertension. World I Gastroenterol 2016; 22: 2725-35.

5. Kanematsu T, Takenaka K, Matsumata T, et al. Limited hepatic resection effective for selected cirrhotic patients with primary liver cancer. Ann Surg 1984; 199: 51-6.

6. Witowski J, Rubinkiewicz M, Mizera M, et al. Meta-analysis of short- and long-term outcomes after pure laparoscopic versus open liver surgery in hepatocellular carcinoma patients. Surg Endosc 2019; 33: 1491-507.

7. Buell JF, Cherqui D, Geller DA, et al. The international position on laparoscopic liver surgery. Ann Surg 2009; 250: 825-30.

8. Wells G, Shea B, O'Connell J, et al. The Newcastle-Ottawa Scale (NOS) for assessing the quality of nonrandomised studies in meta-analysis. 2011. http://www.ohri.ca/programs/clinical_epidemiology/oxford.asp.

9. Hozo SP, Djulbegovic B, Hozo I. Estimating the mean and variance from the median, range, and the size of a sample. BMC Med Res Methodol 2005; 5: 13.

10. Moher D, Liberati A, Tetzlaff J, et al. Preferred reporting items for systematic reviews and meta-analyses: the PRISMA statement. PLoS Med 2009; 6: e1000097.

11. Stroup DF, Berlin JA, Morton SC, et al. Meta-analysis of observational studies in epidemiology: a proposal for reporting. Meta-analysis Of Observational Studies in Epidemiology (MOOSE) group. JAMA 2000; 283: 2008-12.

12. Patriti A, Cipriani F, Ratti F, et al. Robot-assisted versus open liver resection in the right posterior section. J Soc Laparoendosc Surg 2014; 18: e2014.00040.
13. Manoharan B. The use of intercostal and transthoracic trocars for laparoscopic resection of segment VII/VIII dome liver lesions compared to conventional laparoscopic approaches. $2^{\text {nd }}$ Int Consens Conf Laparosc Liver Resection 2014; P4-6.

14. Cho JY, Han HS, Yoon YS, et al. Outcomes of laparoscopic right posterior sectionectomy in patients with hepatocellular carcinoma in the era of laparoscopic surgery. Surgery 2015; 158: $135-41$.

15. Xiao L, Xiang L, Li J, et al. Laparoscopic versus open liver resection for hepatocellular carcinoma in posterosuperior segments. Surg Endosc 2015; 29: 2994-3001.

16. Guro H, Cho JY, Han HS, et al. Laparoscopic liver resection for hepatocellular carcinoma located in segment 7 or 8 . Hepatol Int 2017; 11: S456-7.

17. Scuderi V, Barkhatov L, Montalti R, et al. Outcome after laparoscopic and open resections of posterosuperior segments of the liver. Br J Surg 2017; 104: 751-9.

18. Mariani NM, Santambrogio R, Barabino M, et al. Laparoscopic or open liver resection in cirrhotic patients with hepatocellular carcinoma located in posterior segments. Surg Endosc Other Interv Tech 2017; 31: S150.

19. Araki K, Shirabe K, Yamanaka T, et al. Validation of our surgical strategy of laparoscopic liver resection for postero-superior segments. J Hepatobil Pancreatic Sci 2017; 24A114.

20. Li J, Ren H, Du G, Jin B. A systematic surgical procedure: the '7+3' approach to laparoscopic right partial hepatectomy [deep segment (S) VI, S VII or S VIII] in 52 patients with liver tumors. Oncol Lett 2018; 15: 7846-54.

21. Rhu J, Kim SJ, Choi GS, et al. Laparoscopic versus open right posterior sectionectomy for hepatocellular carcinoma in a high-volume center: a propensity score matched analysis. World J Surg 2018; 42: 2930-7.

22. D'Hondt M, Tamby E, Boscart I, et al. Laparoscopic versus open parenchymal preserving liver resections in the posterosuperior segments: a case-matched study. Surg Endosc 2018; 32: 1478-85.

23. Morikawa T, Ishida M, Takadate T, et al. Laparoscopic partial liver resection improves the short-term outcomes compared to open surgery for liver tumors in the posterosuperior segments. Surg Today 2019; 49: 214-23.

24. Okuno M, Goumard C, Mizuno T, et al. Operative and shortterm oncologic outcomes of laparoscopic versus open liver resection for colorectal liver metastases located in the posterosuperior liver: a propensity score matching analysis. Surg Endosc 2018; 32: 1776-86.

25. Nota C. Robotic versus open minor liver resections of the posterosuperior segments: a multinational, propensity score matched studyo title. $13^{\text {th }}$ World Congr Int Hepato-Pancreato-Biliary Assoc 2018; EP01C-065.

26. Aghayan DL, Fretland ÅA, Kazaryan AM, et al. Laparoscopic versus open liver resection in the posterosuperior segments: a sub-group analysis from the OSLO-COMET randomized controlled trial. HPB 2019; 21: 1485-90.

27. Kluger MD, Vigano L, Barroso R, Cherqui D. The learning curve in laparoscopic major liver resection. J Hepatobiliary Pancreat Sci 2013; 20: 131-6. 
28. Pascual M, Salvans S, Pera M. Laparoscopic colorectal surgery: current status and implementation of the latest technological innovations. World J Gastroenterol 2016; 22: 704-17.

29. Rubinkiewicz M, Truszkiewicz K, Wysocki M, et al. Evaluation of the learning curve of transanal total mesorectal excision: single-centre experience. Videosurgery Miniinv 2020; 15: 36-42.

30. Małczak P, Mizera M, Torbicz G, et al. Is the laparoscopic approach for rectal cancer superior to open surgery? A systematic review and meta-analysis on short-term surgical outcomes. Videosurgery Miniinv 2018; 13: 129-40.

Received: 23.11.2019, accepted: 23.02.2020. 